\title{
Erratum to: Mobility, Migration and Transport: Historical Perspectives
}

\author{
Colin G. Pooley
}

Erratum to:

C.G. Pooley, Mobility, Migration and Transport, Palgrave Studies in Migration History, https://doi.org/10.1007/978-3-319-51883-1

The original version of this book was revised due to a change in the series title. Therefore, we have updated the series title throughout the book.

The updated online version of this book can be found at https://doi.org/10.1007/978-3-319-51883-1

(C) Springer International Publishing 2018

E1

C.G. Pooley, Mobility, Migration and Transport, Palgrave Studies in Migration History, https://doi.org/10.1007/978-3-319-51883-1_7 